\title{
KUALITAS FUNGSI SOSIAL TERHADAP KEBERADAAN TAMAN KOTA PUBLIK DI KOTA SURAKARTA
}

\author{
Prasetyo Febriarto \\ Program Studi Arsitektur Fakultas Sains dan Teknologi \\ Universitas Amikom Yogyakarta \\ febriartop@amikom.ac.id
}

\begin{abstract}
The purpose of this study was to find out the utilization of green open space by looking at the aspects of social functions in the form of recreational activities of park users towards the existence of Taman Monumen 45 Banjarsari (Monjari) city park in Surakarta City. The object of this research is users with various social functions in the form of activities in City Parks in Surakarta City, namely, Taman Monumen 45 Banjarsari (Monjari). Data retrieval techniques use information collected, namely information and data relating to social functions of City Parks in Surakarta City. This information and data is obtained from various sources, in the form of magazines, scientific journals, websites (internet) and books that are relevant to the object of research. The analytical method used in this study uses explorative descriptive analysis. Conducted by observation, observation of the social function of the existence of city parks on user activities by analyzing user activity activities that occur outside and inside the city park in the monument of Taman 45 Banjarsari (Monjari). The study was conducted to find out the social functions (user activity) that occur for five days (Tuesday to Sunday) starting from morning (07.00 - $09.00 \mathrm{am})$, afternoon (12.00-14.00 am), and afternoon (15.00 - $17.00 \mathrm{pm})$ to show the city park good quality and ideal in the city park.
\end{abstract}

Keywords: green open spaces, public city park, social function

\section{Pendahuluan}

Ruang terbuka hijau khususnya di perkotaan sangat dibutuhkan masyarakat baik dari kota maupun dari pinggiran kota atau untuk semua kalangan. Perkotaan kawasan perkotaan dengan pertumbuhan kota dipengaruhi oleh adanya pertumbuhan penduduk yang dapat menjadi pendukung bagi kehidupan diperkotaan. Berdasarkan Permendagri nomor 1 tahun 2007, Ruang Terbuka Hijau Kawasan Perkotaan yang selanjutnya disingkat RTHKP adalah bagian dari ruang terbuka suatu kawasan perkotaan yang diisi oleh tumbuhan dan tanaman guna mendukung manfaat ekologi, sosial, budaya, ekonomi dan estetika.

Berdasarkan Permen PU No.05/ PRT/ M/ 2008, Ruang Terbuka Hijau (RTH) memiliki dua fungsi yaitu Fungsi utama (intrinsik) yaitu fungsi ekologis (pengatur iklim mikro) dan Fungsi tambahan (ekstrinsik) yaitu fungsi sosial budaya, ekonomi dan estetika. Ruang Terbuka Hijau (RTH) dari segi kepemilikan, RTH dibedakan ke dalam RTH publik dan RTH privat. RTH publik maupun privat memiliki beberapa fungsi utama seperti fungsi ekologis serta fungsi tambahan, yaitu sosial budaya, ekonomi, estetika/arsitektural. Khusus untuk RTH dengan fungsi sosial seperti tempat istirahat, sarana olahraga dan atau area bermain, maka RTH ini harus memiliki aksesibilitas yang baik untuk semua orang, termasuk aksesibilitas bagi penyandang cacat. Terkait dengan fungsi sosial dimana kehidupan diperkotaan terdapat masyarakat yang beraktivitas didalamnya. Masyarakat dengan berbagai rutinitas, aktivitas dengan mobilitas yang tinggi. Masyarakat dengan mobilitas yang tinggi tentunya banyak menghabiskan waktunya di luar rumah sehingga dapat mempengaruhi aktivitasnya dan menyita waktu. Butuh keseimbangan aktivitas padat dengan aktivitas santai dimana keleluasaan manusia di dalam ruang tersebut untuk mampu berinteraksi sosial dan komunikasi. Adanya Ruang Terbuka Hijau Kawasan Perkotaan (RTHKP) masyarakat bisa menggunakan sebagai waktu untuk aktivitas sosial seperti olahraga, rekreasi, diskusi atau kegiatan yang bersifat nyaman. Kegiatan atau aktivitas tersebut termasuk dalam rekreasi. Aksesbilitas menuju Ruang Terbuka Hijau (RTH) harus baik, cepat dan secara visual dapat terlihat jelas khususnya di daerah pusat kegiatan yang padat dimana ruang tersebut berupa Taman kota yang bersifat publik.

Menurut Beer, AR (2003) dalam Hakim, 2014:25,Taman kota menjadi area rekreasi dan istirahat ke penghuni kota dan ruang terbuka hijau sangat penting dalam menjaga keanekaragaman kehidupan di dalam kota, menjaga kualitas udara dan suhu kota serta kualitas air. Berdasarkan Permen PU No.05/PRT/M/2008, menyatakan Taman Kota adalah lahan terbuka yang berfungsi sosial dan estetik sebagai sarana kegiatan rekreatif, edukasi atau kegiatan lain pada tingkat kota.

Ruang Terbuka Hijau (RTH) berupa taman kota yang ada di Kota Surakarta yang berada di pusat kegiatan yaitu Taman Monumen 45 (Monjari). Keberadaan taman kota dapat menciptakan kondisi kota yang indah, sejuk dan nyaman serta menunjukan sebuah kota yang baik dan ideal. Salah satu fungsi taman kota sebagai fungsi sosial yang berkaitan erat dengan aktivitas 
rekreasi pengguna sangat penting untuk mengetahui aktivitas apa saja yang terjadi di taman kota tersebut. Permasalahannya yaitu apa yang menyebabkan taman kota taman Monumen 45 Banjarsari (Monjari) begitu penting dengan melihat kondisi eksisting taman kota publik yang berhubungan fungsi sosial. Pertanyaan penelitian sebagai berikut:

1. Bagaimana kondisi eksisting fungsi sosial berupa kegiatan rekreasi taman kota di Kota Surakarta?

2. Kegiatan fungsi sosial seperti apa yang mempengaruhi intensitas pemanfaatan taman kota di Kota Surakarta?

3. Kesimpulan dan saran dengan keberadaan taman kota di Kota Surakarta?

Tujuan dari penelitian ini adalah untuk mengetahui pemanfaatan ruang terbuka hijau dengan melihat dari aspek fungsi sosial berupa aktivitas rekreasi pengguna taman terhadap keberadaan taman kota Taman Monumen 45 Banjarsari (Monjari) di Kota Surakarta.

\section{Tinjauan Pustaka}

Teori Ruang Terbuka Hijau dan Teori Rekreasi Untuk Analisa Fungsi Sosiasl Terhadap Taman Kota

Tujuan Penyelenggaraan Ruang Terbuka Hijau (RTH)

1. Tujuan penyelenggaraan RTH adalah:

a. Menjaga ketersediaan lahan sebagai kawasan resapan air;

b. Menciptakan aspek planologis perkotaan melalui keseimbangan antara lingkungan alam dan lingkungan binaan yang berguna untuk kepentingan masyarakat;

c. Meningkatkan keserasian lingkungan perkotaan sebagai sarana pengaman lingkungan perkotaan yang aman, nyaman, segar, indah, dan bersih.

2. Fungsi Ruang Terbuka Hijau (RTH)

RTH memiliki fungsi sebagai berikut:

a. Fungsi utama (intrinsik) yaitu fungsi ekologis:

- Memberi jaminan pengadaan RTH menjadi bagian dari sistem sirkulasi udara (paru-paru kota);

- Pengatur iklim mikro agar sistem sirkulasi udara dan air secara alami dapat berlangsung lancar;

- Sebagai peneduh;

- Produsen oksigen;

- Penyerap air hujan;

- Penyedia habitat satwa;

- Penyerap polutan media udara, air dan tanah, serta;

- Penahan angin.

b. Fungsi tambahan (ekstrinsik) yaitu:

c. Fungsi sosial dan budaya

- Menggambarkan ekspresi budaya lokal
- Merupakan media komunikasi warga kota

- Tempat rekreasi

- Wadah dan objek pendidikan, penelitian dan pelatihan dalan mempelajari alam

d. Fungsi ekonomi:

- Sumber produk yang bisa dijual, seperti tanaman bunga, buah, daun, sayurmayur;

- Bisa menjadi bagian dari usaha pertanian, perkebunan, kehutanan dan lain-lain.

e. Fungsi estetika:

- Meningkatkan kenyamanan, memperindah lingkungan kota baik dari skala mikro: halaman rumah, lingkungan permukimam, maupun makro: lansekap kota secara keseluruhan;

- Menstimulasi kreativitas dan produktivitas warga kota;

- Pembentuk faktor keindahan arsitektural;

- Menciptakan suasana serasi dan seimbang antara area terbangun dan tidak terbangun.

Karena meningkatnya kebijakan perencanaan urbanisasi dan densifikasi, orang cenderung kurang hidup dengan lingkungan area hijau. Lingkungan estetis yang menarik dapat meningkatkan kesejahteraan dengan meningkatkan kepuasan, keterikatan, dan rasa tanggung jawab pribadi. Pada gilirannya, stres, perasaan kemarahan, agresi dan frustrasi bisa juga berkurang. Orang yang hidup dengan tekanan kerja, kebisingan perkotaan, dan stres lainnya didorong untuk sering mencari bantuan melalui tempat rekreasi outdoor seperti kawasan padang gurun dan taman kota (publik) (Hartig, 2003). Area hijau diasumsikan merangsang penduduk perkotaan untuk memilih aktivitas fisik yang sehat (mis. berjalan, bersepeda, dll) dan memilih kegiatan sehat ini sebagai moda transportasi. Orang menghabiskan lebih banyak waktu di daerah lingkungan hijau lingkungan cenderung mempertahankan perilaku sehat mereka. Selain itu, Ruang hijau yang menarik adalah lingkungan yang bisa menjadi titik fokus untuk beberapa interaksi sosial informal. (Methinee Khotdee, et al 2012).

Ruang terbuka Hijau/ruang hijau juga berkaitan dengan ruang publik. Ruang publik mendukung aktivitas fisik, bertemu teman atau keluarga, ikut serta dalam kegiatan santai, menikmati alam dan mengamati orang lain (Saffer, 2008). Kegiatan ini membantu menyatukan orang, mengurangi perilaku sosial negatif, dan memberikan sosial budaya yang signifikan manfaat seperti kepuasan masyarakat dan pengurangan kejahatan (Brown, Shcebella, \& Weber, 2014; Rasidi, Jamirsah, \& Said, 2012). Selain itu, mereka 
membantu memenuhi kebutuhan manusia akan interaksi sosial (Kazmierczak, 2013).

Peran utama ruang terbuka publik adalah mempromosikan interaksi sosial melalui kegiatan sosial. Dalam bukunya Life Between Buildings, Gehl (2011) menyatakan fakta bahwa ruang terbuka publik dapat membuka atau mengecualikan peluang untuk interaksi sosial. Situasi ini menuntut untuk dapat diakses dan ruang inklusif yang dibentuk oleh prinsip-prinsip berikut: (1) Menghindari tebal hambatan seperti dinding atau penghalang yang menghalangi jarak pandang antara manusia; (2) mendorong jalur berjalan dan bersepeda daripada jalan-jalan mobil, dan (3) mengintegrasikan beragam kegiatan dan variasi orang berfungsi bersama. (Amine Moulay, et al 2017)

\section{Teori Rekreasi}

1. Defenisi Rekreasi

Menurut Dini Rosdiani dalam buku "pendidikan Rekreasi "mengatakan Rekreasi berasal dari

a. Bahasa Yunani yaitu "Recreare " yang berarti diperkenankan kepada setiap orang untuk berbuat sesuatu yang di kehendakinya, Berasal dari "Re" artinya kembali lalu " Creare " artinya aktivitas/kegiatan.

b. Bahasa Perancis " Crearer " artinya membentuk dan mencipta

c. Bahasa Inggris "To Create" artinya menciptakan, menghasilkan (sesuatu yang baru), " Recreation " artinya kembali menciptakan atau kembali membentuk.

Maka dapat ditarik kesimpulan bahwa rekreasi adalah usaha yang dilakukan oleh manusia/seseorang dalam upaya mengembalikan keadaan kondisi fisik pada semula yaitu mencapai keadaan seimbang baik fisik, mental maupun emosionalnya setelah sebelumnya beraktivitas yang hampir rutinitas.

Menurut Kamus Besar Bahasa Indonesia, Rekreasi adalah penyegaran kembali badan dan fikiran, sesuatu yang menggembirakan hati dan menyegarkan seperti piknik; kita memerlukan rekreasi setelah bekerja; berekreasi: mencari hiburan; bermain-main santai; bersenang-senang.

2. Ciri-ciri Rekreasi, sebagai berikut :

a. Bersifat fisik, mental dan sosial.

b. Bentuk Kegiatan yang bebas.

c. Ada motivasi untuk melakukan kegiatan.

d. Adanya waktu senggang.

e. Tidak ada paksaan /atas kemauan sendiri.

f. Bersifat umum.

g. Secara sungguh-sungguh.

h. Sifatnya fleksibel.

i. Adanya hasil sampingan

3. Aktifitas Rekreasi
Menurut Bovy dan Lawson (1977) dalam a Handbook of Physical Planning, aktifitas rekreasi dikelompokkan dalam 5 kategori:

1. Kegiatan yang dilakukan di dalam dan sekeliling rumah, seperti menonton TV, membaca, mendengarkan musik, berkebun, dan sebagainya.

2. Kegiatan dengan interaksi sosial seperti menonton film di bioskop, berbelanja, makan di restoran, kunjungan keluarga, dan sebagainya.

3. Kegiatan yang melibatkan seni budaya (kunjungan pameran seni, teater, konser musik).

4. Kegiatan olahraga, seperti berenang, bola kaki, voli, golf, dan sebagainya.

5. Kegiatan outdoor tidak resmi, seperti jalanjalan, piknik.

Penelitian lain telah menunjukkan bahwa keinginan untuk beristirahat dan rileks secara konsisten mendorong kunjungan taman di berbagai populasi (Chavez \& Olson, 2009). Meski motivasi menghasilkan informasi penting mengapa Orangorang terlibat dalam rekreasi berbasis alam, mereka tidak harus menunjukkan dimana rekreasi ini terjadi. Dengan demikian, penelitian mengidentifikasi preferensi situs yang spesifik dan hubungannya dengan motivasi yang beragam dan pengalaman semakin relevan. Misalnya, penelitian memiliki menunjukkan bahwa tingkat aktivitas fisik di seluruh kelompok demografis di taman umumnya merupakan yang tertinggi di daerah maju di sekitar jalan beraspal, olahraga ladang, lapangan, dan taman bermain sementara tempat penampungan piknik terdekat (Floyd et al., 2008; Kaczynski et al., 2008). (Jason W. Whiting, et al 2017)

\section{Pengertian Fungsi sosial terhadap taman kota di Kota Surakarta}

Berdasarkan Permen PU No. 05/PRT/M/2008 dinyatakan bahwa, taman kota adalah lahan terbuka yang berfungsi sosial dan estetik sebagai sarana kegiatan rekreasi, edukasi, atau kegiatan lain pada tingkat kota. Bagian dari ruang terbuka suatu kawasan perkotaan yang dirancang, disediakan dengan diisi oleh tumbuhan dan tanaman yang dapat menciptakan kondisi kota yang indah, sejuk, nyaman dan sejahtera untuk mengakomodasi fungsi sosial yang berkaitan erat dengan aktivitas pengguna seperti kegiatan rekreasi, kegiatan olahraga, bermain, berinteraksi dengan tujuan untuk menunjukan sebuah kota yang berkualitas baik dan ideal. (Sumber: olahan penulis)

\section{Metode Penelitian}

Metode Penelitian

Penelitian deskriptif eksploratif, menganalisis dan menyajikan data secara terstruktur agar mudah dipahami dan disimpulkan. Tujuan untuk menggambarkan keadaan lingkungan sekitar 
di lokus (taman), tidak dimaksudkan untuk menguji hipotesis tertentu tetapi hanya menggambarkan apa adanya suatu variabel, gejala atau keadaan.

Dilakukan dengan cara menganalisis fungsi sosial terhadap keberadaan taman kota. dianalisis kegiatan aktivitas yang terjadi di luar dan di dalam taman kota. Penelitian dilakukan untuk mengetahui fungsi sosial yang terjadi untuk menunjukan taman kota yang berkualitas baik dan ideal.

\section{Teknik Pengumpulan Data}

Data Primer akan dilakukan dengan observasi adalah pengamatan kualitatif secara langsung oleh peneliti untuk mengambil data-data berdasarkan kondisi di lokasi penelitian. Peneliti mencatat dan mendiskripsikan aktivitas pengguna taman (masyarakat) di dalam dan di luar taman kota.

Data sekunder dilakukan memanfaatkan dokumen yang sudah ada, berupa peraturan pemerintah yang berkaitan dengan ruang terbuka hijau, taman kota dan fungsi sosial. Studi literatur berupa jurnal-jurnal terkait dengan fungsi sosial, rekreasi, taman kota dan ruang terbuka hijau.

\section{Tahapan penelitian:}

1. Tahapan persiapan penelitian

a. Survey awal, dengan mengenali permasalahan yang ada di lapangan.

b. Pengumpulan data, berupa peta dasar dan data tentang kondisi iklim kota Surakarta.

c. Identifikasi data awal, mengenali data dan menyusun data untuk keperluan kesimpulan awal dan penentuan variabel yang dijadikan pegangan untuk tahap survei kedua untuk melihat temuan di lokasi penelitian.

2. Tahapan penelitian

Dokumentasi dilakukan untuk mengumpulkan data sekunder yang digunakan untuk melengkapi data primer (observasi/pengukuran) yang telah diperoleh.

3. Tahapan analisis

a. Tahap identifikasi lapangan dan pengumpulan data.

b. Reduksi data, yaitu sebagai proses seleksi, pemfokusan, pengabstrakan, transformasi data kasar yang ada di lapangan langsung, dan diteruskan pada waktu pengumpulan data.

c. Penyajian data, yaitu rangkaian organisasi informasi yang memungkinkan penelitian dilakukan. Penyajian data diperoleh berbagai jenis, jaringan kerja, keterkaitan kegiatan atau tabel.

d. Penarikan kesimpulan, yaitu dalam pengumpulan data, peneliti harus mengerti dan tanggap terhadap sesuatu yang diteliti langsung di lapangan

\section{Hasil Penelitian dan Pembahasan}

Tahapan Penelitian Fungsi Sosial Terhadap Taman Kota. Proses penelitian dilakukan melalui beberapa tahap:

1. Dipilih lokasi berdasarkan waktu berkumpulnya, kepadatan aktivitas, akses taman di kota.

2. Pengamatan, pencatatan, dokumentasi data selama 5 (lima) hari, Selasa, 5 September sampai dengan Minggu, 10 September 2017. Dilakukan pengamatan kondisi eksisting, sebanyak tiga waktu pengukuran yaitu: pagi (07.00 WIB - 09.00 WIB), siang (12.00-14.00 WIB), dan sore $(15.00-17.00 \mathrm{WIB})$.

3. Mengkaji kondisi lokasi obyek penelitian dengan batasan Taman kota yang bersifat publik dan fungsi sosial. Fungsi sosial berupa kegiatan rekreasi yang terjadi di taman kota Taman Monumen 45 Banjarsari (Monjari).

4. Menganalisis kegiatan aktivitas yang terjadi di luar taman atau di dalam taman kota.

Fungsi Sosial Terhadap Taman Kota di Taman Monumen 45 Banjarsari (Monjari)

a. Dari hasil pengamatan bahwa fungsi dengan aktivitas rekreasi di Taman Monumen Banjarsari (Monjari) Surakarta ini adalah

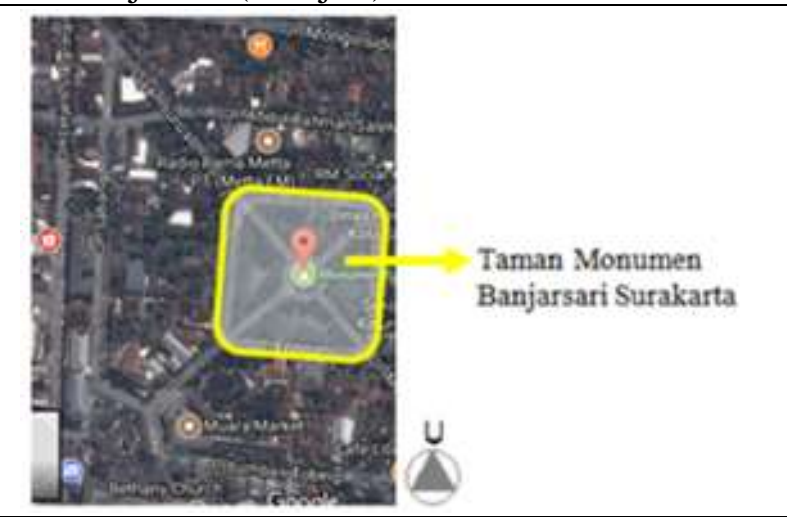

Gambar 1. Peta Taman

Sebelum masa pemerintahan Jokowi, Monumen 45 Banjarsari terbengkalai selama bertahun-tahun. Bahkan disebelah barat monumen ini dulu terdapat sederet pedagang yang menjadikannya sebagai Pasar Barang Bekas dan terkenal dengan nama Pasar Klithikan. Aktivitas ini dirasa merusak fungsi Monumen 45 Banjarsari sebagai taman kota.

Letak dan posisi taman ini yang sangat strategis dan ditengah kepadatan kota yang dirasa perlu membutuhkan ruang terbuka hijau publik kota. Di sisi sebelah selatan Monumen 45 Banjarsari yang juga menjadi gerbang pintu masuk Taman Banjarsari terdapat tulisan Villa Park Banjarsari. Monumen 45 Banjarsari ini persisnya terletak di Kelurahan Setabelan, Kecamatan Banjarsari. Taman ini sangat dekat dengan Pasar Legi. Menuju arah barat, monumen ini sangat dekat dengan Stasiun Balapan, sedangkan menuju arah selatan ke kawasan Mangkunegaran. Menuju arah utara ke Terminal Tirtonadi. 


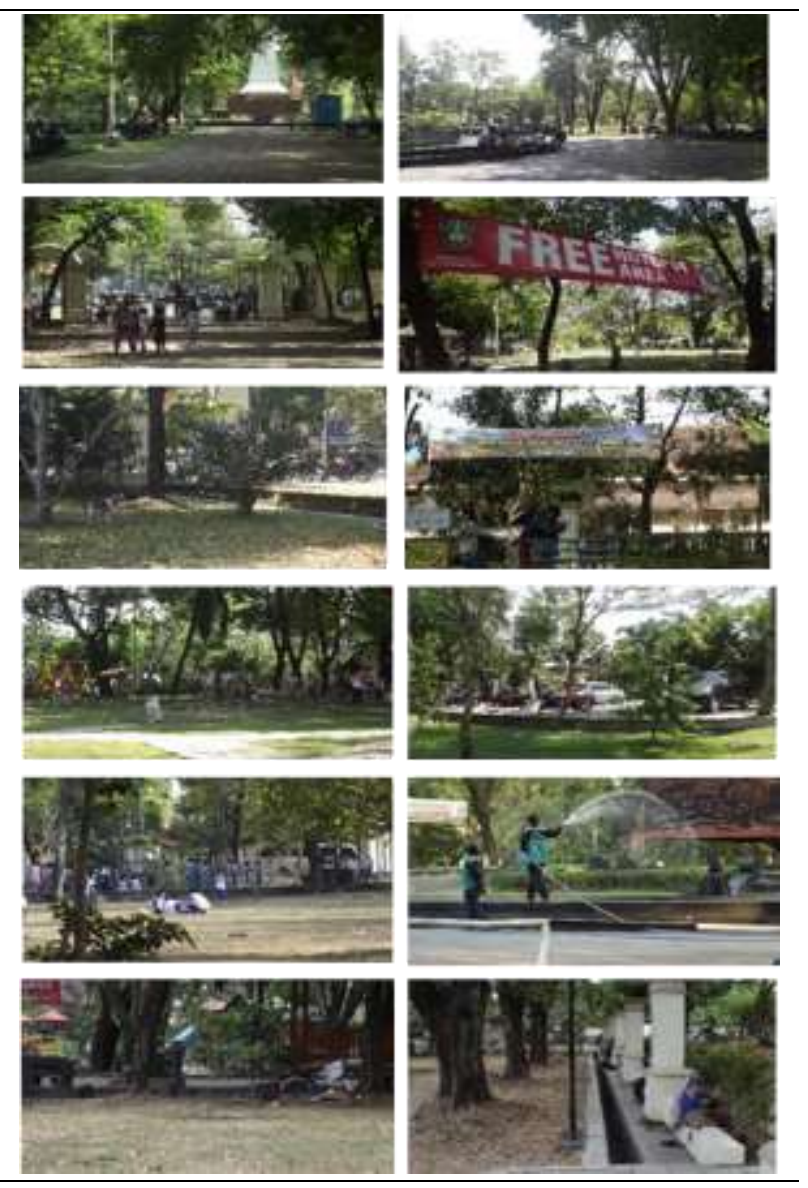

Gambar 2. foto kondisi eksisting aktivitas

Tahun 2006, Walikota Jokowi mengembalikan fungsi Monumen 45 Banjarsari seperti sediakala sebagai tempat rekreasi warga Solo. Para pedagang Pasar Barang Bekas di area ini direlokasikan ke daerah Semanggi dengan nama baru yaitu Pasar Klitikan Notoharjo.

Pemeliharaan yang baik dari Pemerintah Kota, dimanfaatkan masyarakat sebagai wahana edukasi sejarah sekaligus sebagai area publik untuk berolahraga dan berekreasi. Taman Banjarsari sangat bagus, hal ini ditandai dengan semakin banyaknya warga yang menggunakan taman sebagai ruang terbuka hijau publik. Dan memang pengamatan selama 5 (lima) hari bisa dikatakan taman ini ramai pengunjung dan aktivitasnya hampir sama. Memang lokasi taman ini strategis inilah yang menjadikan taman ini selalu ramai. Tak hanya dikunjungi oleh masyarakat sekitar saja. Taman ini juga biasanya digunakan untuk melepas lelah sejenak. Taman ini tetap terasa sejuk dan nyaman sekali untuk disinggahi. Terutama saat sore hari, taman ini begitu teduh dan cocok sekali. Perawatan terhadap taman ini termasuk baik karena ada petugas perawat taman. Fungsi umum dari taman kota ini banyak sekali yaitu mayoritas untuk berekreasi meliputi; tempat bersantai dan berolahraga, komunikasi sosial.

Tabel 1. waktu aktivitas di Taman Monumen Banjarsari

\begin{tabular}{|c|c|c|c|}
\hline Thari & Dowlui & DidDalam Fanan & 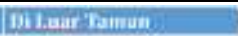 \\
\hline Mclata:Mlugra & $\begin{array}{l}0700-09.00 \\
12.00-14.00 \\
15.00-17.00\end{array}$ & 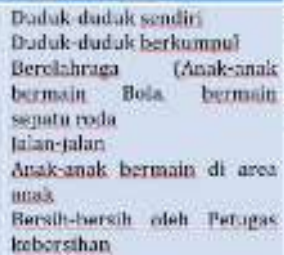 & 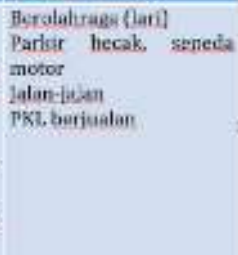 \\
\hline
\end{tabular}

Temuan pada Taman Kota Publik di Taman Monumen 45 Banjasari (Monjari) Kota Surakarta

Setelah proses analisis fungsi sosial berupa aktivitas pengguna rekreasi telah dilakukan, maka muncul temuan pada penelitian di taman Monumen 45 Banjarsari (Monjari) dimana apa yang menjadi faktor taman Monumen 45 Banjarsari (Monjari) begitu penting di fungsikan:

a. Taman Monumen 45 Banjarsari secara keseluruhan dibagi dalam empat bagian yaitu ruang olahraga, ruang bermain, ruang bersantai dan ruang vegetasi.

b. Di luar taman yaitu:

- Aspek Aksesbilitas, letaknya sangat strategis karena berada dekat dengan stasiun kota solo yaitu stasiun Solo Balapan. Sarana transportasi untuk menuju ke taman kota Monumen Perjuangan 45 Banjarsari cukup mudah, bisa menggunakan kendaraan pribadi dan umum untuk mencapai lokasi taman ini.

- Aspek penataan taman yang juga berimbas pada penataan di luar taman yaitu elemen keras perbaikan perkerasan jalan dengan pengaspalan jalan yang rapi. Elemen lunak dimana terdapat vegetasi yang tinggi dan rindang yang memberikan keteduhan dikarenakan naungan tajuk vegetasi yang lebar.

c. Di dalam taman yaitu:

Aspek penataan taman yang rapi, bersih aman dengan terdapat elemen keras yaitu tempat duduk yang nyaman, dilengkapi perkerasan untuk pejalan kaki yang nyaman, rapi bersih dan elemen lunak

Aspek kelengkapan fasilitas, taman ini dilengkapi dengan fasilitas demi memberikan kenyamanan, memanjakan pengguna. Elemen lunak dimana terdapat vegetasi yang tinggi dan rindang yang memberikan keteduhan dikarenakan naungan tajuk vegetasi yang lebar.

Aspek kelengkapan fasilitas seperti street furniture taman berupa lampu taman, bangku, Gazebo untuk tempat istirahat. Taman ini juga dilengkapi dengan teknologi internet berupa Wifi. Tersedianya fasilitas untuk bermain anak, adanya ruang hijau lapang yang bisa digunakan untuk kegiatan olahraga seperti sepakbola, senam atau bisa untuk acara event tertentu. Tersedia juga fasilitas parkir kendaraan bermotor, sepeda. 


\section{Kesimpulan dan Saran}

Kesimpulan yang didapat yaitu:

1. Taman kota di kota Surakarta yang banyak dikunjungi masyarakat dan aktivitas rekreasinya padat yaitu taman Monumen 45 Banjarsari (Monjari) termasuk taman kota yang berkualitas baik dan ideal

2. Adanya pemeliharaan yang baik dari Pemerintah Kota, sehingga dapat dimanfaatkan masyarakat sebagai wahana edukasi sejarah sekaligus sebagai area publik untuk berolahraga dan berekreasi.

Saran yang didapat dari penelitian ini adalah:

1. Perlu perawatan secara rutin dan tetap dipantau agar tidak menjadi kumuh, kotor lagi dan menjadikan enak dilihat serta dapat menjadi daya tarik bagi masyarakat yang ingin menikmati taman dalam berkegiatan rekreasi. Hal tersebut menjadikan taman kota yang berkualitas baik dan ideal.

2. Perlu ruang atau tempat yang tidak terlalu besar untuk berjualan oleh PKL karena keberadaan taman tersebut mengundang pedagang kaki lima (PKL) untuk berjualan yang pembelinya merupakan pengunjung taman Monumen 45 Banjarsari (Monjari).

\section{Daftar Pustaka}

Hakim, Rustam. 2007. Komponen Perancangan Arsitektur Lansekap: Prinsip-Unsur dan Aplikasi Desain. Jakarta: Penerbit PT Bumi Aksara.

Rosdiani, Dini. 2015. Pendidikan Rekreasi, Bandung: Alfabeta

Amine Moulay, Norsidah Ujang \& Ismail Said. (2017). Legibility of neighborhood parks as a predicator for enhanced social interaction towards social sustainability. Cities. 61, 5864.

Jason W. Whiting, Lincoln R. Larson, Gary T. Green \& Chuck Kralowec. (2017). Outdoor recreation motivation and site preferences across diverse racial/ ethnic groups: A case study of Georgia state parks. Journal of Outdoor Recreation and Tourism 18. 10-21

Methinee Khotdee, Wichitra Singhirunnusorn, and Nopadon Sahachaisaeree. (2012). Effects of Green Open Space on Social Health and Behaviour of Urban Residents: A Case Study of Communities in Bangkok. Procedia - Social and Behavioral Sciences 36. $449-455$

Peraturan menteri pekerjaan umum nomor: 05/prt/m/2008 tentang pedoman penyediaan dan pemanfaatan ruang terbuka hijau di kawasan Perkotaan ".pdf

Peraturan menteri dalam negeri nomor: 01 tahun 2007 tentang penataan ruang terbuka hijau kawasan perkotaan ".pdf 